\title{
SEQUENCING OF NEW ZEALAND'S TOMATO SPOTTED WILT VIRUS ISOLATES
}

\author{
R.A. LISTER, J.D. FLETCHER and G.M. TIMMERMAN-VAUGHAN
}

\author{
Plant \& Food Research, Private Bag 4704, Christchurch, New Zealand
}

Corresponding author: ListerR@crop.cri.nz

The capsid protein genes of thirteen isolates of Tomato spotted wilt virus (TSWV) (Tospovirus) occurring in New Zealand have been sequenced. TSWV is a thrips-vectored virus causing serious damage in field and covered crops. With recent new incursions of thrips species and tospoviruses it was considered of interest to identify what, if any, sequence variation occurs in the New Zealand TSWV isolates, both from a temporal and geographic perspective. The material chosen for sequencing was sourced from fresh glasshouse and field samples and also from samples that had been stored frozen for several years. The oldest TSWV isolate was collected in 1992 and stored frozen since then, and the most recently collected was from fresh material in 2008. Samples were obtained from several geographic locations throughout New Zealand. When compared to the worldwide TSWV capsid gene sequence data held in GenBank, cluster analysis of the sequence data has placed the New Zealand isolates into distinct groups. Observations of the most closely related strains on a global scale may provide clues to the country of origin from which historic TSWV incursions into New Zealand originated.

\section{DETECTING A TOSPOVIRUS IN TRAPPED THRIPS}

\author{
R.A. LISTER, M-C. NIELSEN, M.M. DAVIDSON, J.D. FLETCHER and \\ G.M. TIMMERMAN-VAUGHAN
}

\author{
Plant \& Food Research, Private Bag 4704, Christchurch, New Zealand
}

Corresponding author: Listerr@crop.cri.nz

Thrips vector tospoviruses, which worldwide cause disease epidemics in a wide range of economically important crops. Of the approximately 5000 species of thrips, 11 are known to vector one or more of the 14 recognised Tospovirus species. In New Zealand, only three tospoviruses and two vectors have been recorded. Frankliniella occidentalis and Thrips tabaci vector Tomato spotted wilt virus (TSWV), while T. tabaci vectors Iris yellow spot virus (IYSV), and Impatiens necrotic spot virus (INSV) is vectored primarily by $F$. occidentalis. Frankliniella occidentalis is also known to vector three other tospoviruses not yet recorded in New Zealand. It was possible to detect the presence of a tospovirus (TSWV) from thrips (F. occidentalis) trapped on sticky boards for $24 \mathrm{~h}$ and $1,2,3$ or 4 weeks using ELISA and RT-PCR techniques. ELISA provides a rapid and economical screening technique provided antibodies are commercially available for a given tospovirus. However, the use of RT-PCR may allow the development and use of universal primers to detect the presence of any Tospovirus, which could then be further identified using specific Tospovirus primers. 